Volume 11, Issue 12, December 2020, pp. 1700-1708. Article ID: IJM_11_12_156

Available online at http://iaeme.com/Home/issue/IJM?Volume $=11 \&$ Issue $=12$

Journal Impact Factor (2020): 10.1471 (Calculated by GISI) www.jifactor.com

ISSN Print: 0976-6502 and ISSN Online: 0976-6510

DOI: 10.34218/IJM.11.12.2020.156

\title{
QUALITATIVE SURVEY FOR LAVATORY SPACES; CASE STUDY ON TOILET AT CANSELOR TUANKU MUHRIZ'S HOSPITAL, THE NATIONAL UNIVERSITY OF MALAYSIA (UKM)
}

\author{
A.I. Che-Ani and N.M. Tawil \\ Department of Architecture and Built Environment, \\ The National University of Malaysia, Malaysia
}

A.H. Hussain and R.A. Latiff

Citra Centre, The National University of Malaysia, Malaysia

\section{S. Johar and N.H. Mahmood}

Department of Architecture and Built Environment, The National University of Malaysia, Malaysia

\begin{abstract}
Toilets are a basic necessity in daily life and the frequency of toilet use tends to cause defects and damage to that facility. Severe toilet conditions not only affect the level of comfort and satisfaction of users, but toilets that are not well maintained may also endanger the user safety. Therefore, the purpose of this paper is to obtain the complaints from toilet users on the quality provided and suggestions for improvement when using the toilet at Canselor Tuanku Muhriz's Hospital, UKM. To obtain feedback on toilet damage issue, a questionnaire survey using qualitative method approach was conducted and distributed randomly to UKM Hospital citizens using digital platform. The research results provide insights into various types of toilet defects that commonly occur in hospitals that can cause problems to patients and staff who use the toilet. The originality of this research is to identify the types of toilet defects that often occur in University Medical Centre from the aspect of users and its safety impact on patients.
\end{abstract}


Key words: toilet defect, satisfaction of toilet use, toilet in Hospital

Cite this Article: A.I. Che-Ani, N.M. Tawil, A.H. Hussain, R.A. Latiff, S. Johar and N.H. Mahmood, Qualitative Survey for Lavatory Spaces; Case Study on Toilet at Canselor Tuanku Muhriz's Hospital, The National University of Malaysia (UKM), International Journal of Management, 11(12), 2020, pp 1700-1708.

http://iaeme.com/Home/issue/IJM?Volume=11\&Issue=12

\section{INTRODUCTION}

Chancellor Tuanku Muhriz's Hospital, UKM was established on 2nd November of 1993 and has received many patients as well as visits from medical students and hospital staff working there. During the nearly three decades of its establishment there were many building defects that occurred and damage to the facilities provided. Buildings in hospital are not exempt from the problem of building defects. This is because most government buildings deal with problems such as cracks, fading dyes, sealant failures, efflorescence, dampening of buildings, corrosion, deflection and plaster delaminating that cause building materials to deteriorate and require workers to do repairs (Shittu, A. A. et al., 2013). Building defects will occur in buildings that are getting older and the most affected space is the toilet due to its frequency of use. Damaged and defects toilet condition affects patients who use the toilet due to its failure to function in a role. Design features of toilets that are increasingly shabby and not user friendly also will endanger the patient.

Among the problems that occur in hospital toilet is receiving too many patient over time that practice varying usage ethics resulting the increasing rate of toilet defects. Secondly, the toilets in the hospital are poor in terms of function and fail in design that has burdened the users, especially person with disabilities users and wheelchair patients. The limited financial allocation has limited the remedial and maintenance work from being done. Lastly, the problem that is difficult to curb were comes from the ethics of users who lack a high level of awareness that ultimately contributes to the destruction of public property. Apart from users, the work ethic of cleaner staff that carelessly cleans the toilet does not solve the issue of toilet defects that occur. This problem arises when there is no cooperation from all parties to combat this issue.

The purpose of this paper is to obtain the complaints from toilet users on the quality provided and suggestions for improvement when using the toilet at Canselor Tuanku Muhriz's Hospital, UKM. This research is able to categorize various types of toilet defects that commonly occur in hospitals that can cause problems to patients and staff who use the toilet. For this research, a questionnaire survey using qualitative method approach was conducted and distributed randomly to UKM Hospital citizens using digital platform. Respondents were randomly selected consisting of UKM users and staff themselves in expressing their opinions on improvements and the quality of facilities provided at UKM toilets. Due to the lack of personal contact between the respondent and the researcher, a questionnaire is the best method to achieve the large sample and distributed widely to the UKM citizens in a short period. The originality and target of this research is to investigate the types of toilet defects that often occur in University Medical Centre from the aspect of users because there is no previous study that highlights research on defects that occur in the hospital toilet and its psychological impact on patients.

The output of this research is able to categorize the types of defects and damage that often occur in the toilet that affects both patients and users in the hospital. This study also obtains complaints and feedback from the user perspective on improvements that can be made by management to improve defects in the toilet. The responsibility and awareness of those involved in designing, managing and maintaining toilets in hospitals has been emphasized in 
Qualitative Survey for Lavatory Spaces; Case Study on Toilet at Canselor Tuanku Muhriz's Hospital, The National University of Malaysia (UKM)

this research so that toilets in hospitals are safe and can be used well, especially for wheelchair patients.

\section{FACTOR AND EFFECT OF BUILDING DEFECTS}

Building defects is definitely will be occur to all building due to several factors such as age, user ethics and maintenance. Yacob, S. et al. (2019) described building defects as the building losing its function of providing proper service to users. Poorly maintained buildings tend to suffer from damage to the facilities available in the building and the toilet space is among the areas with the most defects. This research was supported by the research conducted by Wei \& Thomas (2015) against 327 houses in South Wales and Southwest England. A total of 3209 defects have been recorded, of which 454 (14.1\%) were the defects in the toilet and were among the highest. On average, every person using the toilet is six times a day together with three years of life in a lifetime toilets (World Toilet Organization 2011) and frequency of toilet use can speed up the defects caused by wear and tear. This problem need to be taken into consideration before it become permanent defects and require high costs to carry out maintenance work.

There are many factors that contributed to building defects that has been highlighted by previous studies. Among the factors that contributed to building defects was highlighted by Mydin et al. (2014) are wood damage, colour blurring of buildings, moisture, peeling paint and insufficient awareness. Then, according to Awol (2016), the main contributing factors of defects based on the level of importance were poor quality of materials, poor construction labour, weakness in building design and poor attitude of residents itself. Next, the another building defects factor also states by Talib et al. (2014) that are caused by lack of maintenance, unwanted site conditions, moisture problems, material damage, ageing of building, poor quality control, lack of training and motivation, poor communication and environmental conditions. Besides that, defects and failures in buildings are also due to climate conditions, location of buildings erected, materials used in construction, types of buildings and alterations of function, lack of building maintenance, poor design, corruption and poor oversight (Ahzahar. N., 2011).

Moreover, Azlan Shah Ali (2013) divides the common defects into three aspects; first, technical involving workmanship or material of an element that does not work as desired and reduces the performance of structural functions. Serious defects in this aspect affect the safety, health and value of the building involved. Secondly, the aesthetic appearance or element of the building are affected and gives an impression on the value or economy of the building. The third involves aspects of the function in which the building cannot function properly.

Ongoing monitoring and initial action should be taken to reduce the rate of defects in the toilet area. This is because failure to curb the damage and defects that occur will gave negative impact on the user and also the building. Md Yusof Hamid and Suriani Ngah Abdul Wahab (2012) states building defects may affect the functionality and performance of building structures resulting in a decline in occupancy rate. The appearance and facade of the building are also affected and gives a bad image of the building in the eyes of the user. Lastly, toilet defects may affect occupant safety and health because of disturbing in inhaled air that contains bacteria that giving an allergic effect to a person.

\section{METHODOLOGY}

This research's main objective is to get the views and complaints from toilet users on the quality and services provided when using the UKM toilet. Therefore, a questionnaire survey using qualitative method was conducted to get feedback on toilet damage issue and user 
suggestions for improvement on toilet in UKM. A questionnaire access was built and shared to UKM Hospital citizens and distributed randomly using digital platform. This online survey method was chosen because it is cheaper and saves time as researchers want to get as much feedback as possible in a short time. The selection of this method is because to get the honest views from the respondents as their identity are not revealed and they can voice all dissatisfaction about the problems in the UKM toilet. This is because the complaints received are also influenced by the research methods conducted because not all respondents are ready and comfortable when they were physically approached by the researcher themselves. All user complaints regarding toilet defects and suggestions for improvement to management to overcome this problem are also accepted to be emphasized in this research. All data recorded from the survey have been analyzed and sorted using Microsoft Excel.

\section{RESULTS AND FINDINGS}

\subsection{Case Study in the Toilet at Canselor Tuanku Muhriz's Hospital, UKM}

The results of this research examine the problems faced by users in UKM when using the toilet based on qualitative survey conducted. Complaint feedback on toilet defects was recorded and divided into several main constructs.

\section{Table 1}

\begin{tabular}{lll}
\hline & \multicolumn{1}{c}{ Construct } & \multicolumn{1}{c}{ User Complaints } \\
\hline i & Toilet Condition & - Floor Tiles are Slippery and Inappropriate \\
& & - Old Ceilings do not Replace \\
& & - Insufficient number of Toilets \\
& & - Leakage From the Upper Pipe \\
& & - Toilets are Often Locked \\
\hline ii & Facilities & - Squat Toilet Provided are not Suitable for Patient \\
& & - Toilet Bowl without a Seat Cover \\
& & - Flush Damaged \\
& & - Water Pipes that are not Equipped with Hoses \\
& & - Low Water Pressure \\
\hline iii & Ventilation and Lighting System & - Absence of Bins \\
& & - Bad Smell enter the Ward and Clinic \\
& & - Staff had to Buy Their own Toilet Fragrance \\
& & - Limited Lighting \\
\hline iv & Maintenance & - Absence of a Ventilation Fan \\
& & - Large number of Users \\
& & - Less Cleaning Frequency \\
& & - No Regular Cleaning Schedule \\
\hline v & Location & - The Cleaner Does Not Clean The Toilet As Required \\
\hline vi & Special Needs & - Toilet Located Far from the Ward \\
& & - Absence of Signage \\
\hline vii & Ethics & - No Toilet available for People With Disabilities \\
& & - No Toilet for Old People to Changing Diapers \\
& & - Non-People With Disabilities Friendly Toilet Design \\
\hline & & - Staff Smoke in the Toilet \\
& - Unethical Toilet User Attitudes \\
& - Lack of Ethics Poster \\
\hline &
\end{tabular}


Qualitative Survey for Lavatory Spaces; Case Study on Toilet at Canselor Tuanku Muhriz's Hospital, The National University of Malaysia (UKM)

\subsection{Discussion on User Complaints against Toilet Defects}

\subsubsection{Toilet Condition}

Among the complaints received about the condition of the toilet in the hospital is the selection of floor tiles that are slippery and inappropriate for patients. The floor tiles are dirty and broken will resulting in injury and danger to users, especially patients who use the toilet. This is a concern because in most countries, hospital falls are safety issue and one of the most common reported (Choi, Y. S. et al., 2011) but a more serious issue is the impact of injuries that occur after a fall (Drahota, A. K. et al., 2013). Management needs to take the initiative to replace damaged tiles with more suitable ones for use in hospital areas. Next, the complaint received was regarding the ceiling which looked old and not been replaced. Deteriorated ceilings pose a danger to users and require maintenance to repair damaged ceilings. Defects in the ceiling usually involve dampness and peeling paint due to the ingress of rainwater that enters through the roof (Tan, S. W. et al., 2014). In addition, the insufficient number of toilets makes it difficult for users coupled with the condition of those with chronic diseases. The insufficient toilets will cause user assembly in waiting for turn in crowded places and more dangerous if they mixed with those with infectious diseases. Next, the problem of leakage that occurs in the toilet becomes a concern of toilet users in UKM hospitals. Leakage from the upper pipes results in moisture which stimulates the growth of mold and fungi that will physically affect the appearance of the building structure and result in various health problems among toilet users (Tan, S. W. et al., 2014). Although this problem is not a new thing but if not taken action can cause problems later. The next complaint received was about the condition of the toilet being constantly locked. This should not happen because the toilet is a public facility that is always used at all times. Coupled with complaints about toilets that are not sufficient to accommodate the large number of users, locked toilets make it difficult for users who want to use it when emergency.

\subsubsection{Facilities}

Among the complaints received from the respondents was the condition of the toilet facilities that could not be used. Facilities such as the squat toilet provided do not meet the needs of users and are not suitable for patients. This is because squatting toilet seats can result in devastating foot injuries involving neurovascular structures and tendons and may require microvascular tissue transfer for definitive wound management (Mohsin, M. et al., 2020). The use of sitting toilets is also friendlier to patients in wheelchairs while using the toilet. In addition, the convenience of a toilet bowl without a seat cover also adds defects to the toilet space because indirectly, the condition of toilet bowls that come in contact with the skin and clothing of patients will cause hygienic toilet problem and bacterial infections (Chien, L.C. and Chien, H.Y., 2014). Next, the damaged toilet flush condition that were complaints by respondents makes them difficult to clean the toilet after use and had to take other initiatives to pump toilets manually. If the situation is faced by an irresponsible user who leaves the toilet without being pumped due to a damaged flush, it will cause the toilet to smell and cause discomfort to other users. The paucity of proper sanitation facilities also may contribute to the spread of waterborne diseases that was happen in many developing countries (Huang, X. et al., 2016). Furthermore, water pipes that are not equipped with hoses and low water pressure make it difficult for users to clean themselves. According to G.Williams and G.Kuczera (2014), water distribution networks throughout the world are ageing and pipe failures can affect users also incur high maintenance costs and extending pipe life is highly desirable for user. This problem can put pressure on toilet users and they will not use the toilet unless there is no choice. The use of toilets in Malaysia is highly dependent on the use of water for personal hygiene, but if the water pipe cannot be used properly it will cause the spread of 
bacterial infections due to imperfect self-cleaning. Then, the absence of bins tends to result in irresponsible users dumping tissues into the toilet which ultimately results in clogged toilets. The lack of bins is faced by most of the cities of developing countries resulting in littering habit (Rathore, P. et. al., 2020) and contributes to toilet dirt. Moreover, the absences of rubbish bins making the toilets dirty especially the toilets that do not use water pipes and use the bidet system (Coswosk, É. D et al., 2019).

\subsubsection{Ventilation and Lighting System}

Ventilation and lighting system factors also affect respondent discomfort. Among the complaints received involving this problem is the bad smell from the toilets that enter the ward and clinic space in the hospital which gives dissatisfaction to the hospital staff and patients. Consequently, there are staffs that had to buy their own toilet fragrance because it is not provided by the management to prevent the toilet from smelling and embarrassing with visitors who use the toilet. Bad smells emitting from a toilet would attract negative social judgment and toilets were mostly constructed at some distance because of the disgust associated with the smell and sight of these structures (Czerniewska, A., et al., 2019). Limited lighting in the toilet and the absence of a ventilation fan to remove odor also make floor being constantly wet because not getting enough lighting. Limited ventilation and lighting will complicate the flow of air in and out and result in a foul odor that occurs in the toilet. Therefore, management needs to take initiatives to overcome the problem in providing other alternatives to give comfort to users from bad smells.

\subsubsection{Maintenance}

Unmanaged maintenance problems receive many complaints from users. The condition of hospitals that always receive visitors and patients increases the number of toilet users in large numbers and tends to cause toilets defects. Coupled with less cleaning frequency by the cleaner and no regular cleaning schedule adds to the problems with the maintenance of the toilet. Toilets need to be maintained and cleaned regularly to ensure comfort to users. Lack of maintenance may affect defects on building facilities and services (Talib et al., 2014) and this happen because building maintenance is conducted during emergency hours only (Mydin et al., 2014). Complaints received from respondents are also the attitude of the cleaner who does not clean the toilet as required cause the toilet is always in a dirty condition. According to Okuntade (2014) and Waziri, B. S. (2016) states that high maintenance and defects in buildings were due to the lack of oversight by responsible authorities. All parties including management, users and cleaners should work together to take the initiative of every complaint received to repair and maintain the toilet from time to time.

\subsubsection{Location}

The location of the toilet also received negative complaints from users. The problem of the location of the toilet located far from the ward makes it difficult for patients to commute to the toilet to clean themselves. Coupled with the lack of adequate hospital staff to help patient to the toilet room will endanger chronic patient to go to the toilet himself. Moreover, the absence of signage confuses and makes it difficult for users to find their way to the toilet. The use of signage is very important to users, especially patients who do not have much energy or time to find the location of the toilet, plus if the location of the toilet is very far from the location of the patient's ward. Management should not overlook this because the provision of signage is important to help users and does not cost a lot to provide it. 
Qualitative Survey for Lavatory Spaces; Case Study on Toilet at Canselor Tuanku Muhriz's Hospital, The National University of Malaysia (UKM)

\subsubsection{Special Needs}

Next, the complaints received are about the special needs of people with disabilities. Among the complaints received was the lack of suitable toilets for people with disabilities in certain areas. Some people with disabilities face various diseases or bone system degradation that limits their physical movement will make it difficult for them to use the toilet (Balaceanu, C. et al., 2019). Although people with disabilities are only a minority, but the good facilities for this group should be provided because the hospital is an area with many wheelchair users. The facilities for the old people to change diapers that were not provided in the toilet are difficult for patients to get more privacy when cleaning themselves and changing diapers. In addition, the conditions and equipment found in people with disabilities toilet that are not user-friendly burden the user and put pressure on them. This is supported by Hignett, S. (2013) who states that poor design can permeate throughout the building system and result in a reliance on behavior changes rather than beginning with the design.

\subsubsection{Ethics}

The problem complained by the respondents regarding user ethics is there are hospital staff who quietly smoke in the hospital toilet area. This should not happen because the image of the hospital that takes care of the patient's health is very contrary to the image of this kind of staff attitude. Furthermore, the hospital area is a non-smoking area has been taken advantage of by irresponsible staff that uses the toilet as a place for them to smoke. There are also certain attitude of users and patients who are unethical and comply with the rules when using public property. This is strongly influenced by the hospital toilets which accept various users who practice the different ethics when using the toilets. This is related to the lack of poster announcements about the ethics of using the toilet that is not able to educate users to maintain their manners when using the toilet. Although the use of posters is a traditional media but it is still effective in promoting informative content in this digital era (Barik, A. L. et al., 2019).

\section{CONCLUSION}

Many respondent were complaints and visualized their dissatisfaction about damage or defects in the toilet facilities in the hospital. Hospital conditions that do not emphasize the design features that are not safe and unable to provide the best toilet facilities will also affect the health of patients. Although this research has concluded that many UKM users are dissatisfied with the UKM toilets that include various aspects, further studies are needed to generalize these findings. Despite there are useful findings in this study, certain limitations in this qualitative survey should be acknowledged, which can be addressed in next research. This research is limited to respondents from Management/ Academic/ Executing Staff, Students and Visitors only without obtaining views from the patient's own experience. This is because this survey is distributed in the UKM website and only UKM citizens can access it. It is hoped that this research limitation can be improved on future research by future researchers. Further research can examine the effects of toilet defects and its relationship to the patients emotional, psychological, behavioral and health when they using the toilet in the hospital. Therefore, in order to develop more comprehensive findings, future studies are needed to further strengthen existing research so that the validity of this research can be better practiced and contributed in the next research.

\section{ACKNOWLEDGEMENTS}

This research was funded by the research grant Strategic Research Fund (KRA-2018-051), Researcher Incentive Grants (GGPM-2019-069) and Fundamental Research Grant Scheme (FRGS/1/2019/SS08/UKM/02/8). 


\section{REFERENCES}

[1] Ahzahar, N. (2011). A study of contribution factors to building failures and defects in construction industry. Procedia Engineering, 249-255.

[2] Awol, A. (2016). Assessment on causes of defect and the maintenance management practices on low cost building (A case study of Jimma Town Condominium). International Journal of Engineering and Technical Research, 151-156.

[3] Azlan Shah Ali. (2013). Teknologi dan pengurusan penyenggaraan bangunan. Kuala Lumpur: Penerbit Universiti Malaya.

[4] Balaceanu, C., Marcu, I., Suciu, G., Dantas, C., \& Mayer, P. (2019, September). Developing a smart toilet system for ageing people and persons with disabilities. In Proceedings of the 6th Conference on the Engineering of Computer Based Systems (pp. 1-4).

[5] Barik, A. L., Purwaningtyas, R. A., \& Astuti, D. (2019). The effectiveness of traditional media (leaflet and poster) to promote health in a community setting in the digital era: A Systematic Review. Jurnal Ners, 14(3), 76-80.

[6] Chien, L.C. and Chien, H.Y. (2014). Disposable toilet hygienic seat cover and laying method thereof. U.S. Patent Application 14/358,018.

[7] Choi, Y. S., Lawler, E., Boenecke, C. A., Ponatoski, E. R., \& Zimring, C. M. (2011). Developing a multi-systemic fall prevention model, incorporating the physical environment, the care process and technology: a systematic review. $J$ Adv Nurs, 67(12), 2501-2524. doi: 10.1111/j.1365-2648.2011.05672.x

[8] Coswosk, É. D., Neves-Silva, P., Modena, C. M., \& Heller, L. (2019). Having a toilet is not enough: the limitations in fulfilling the human rights to water and sanitation in a municipal school in Bahia, Brazil. BMC public health, 19(1), 137.

[9] Czerniewska, A., Muangi, W. C., Aunger, R., Massa, K., \& Curtis, V. (2019). Theory-driven formative research to inform the design of a national sanitation campaign in Tanzania. PloS one, 14(8), e0221445.

[10] Drahota, A. K., Ward, D., Udell, J. E., Soilemezi, D., Ogollah, R., Higgins, B., . . Severs, M. (2013). Pilot cluster randomised controlled trial of flooring to reduce injuries from falls in wards for older people. Age Ageing. doi: 10.1093/ageing/aft067

[11] G.Williams, G.Kuczera. (2014). Analyzing SCADA to understand the contribution of hydraulic pressures to trunk-main failure. Procedia Engineering, 89 ( 2014 ) 1452 - 1459.

[12] Hignett, S. (2013). Why design starts with people. The Health Foundation, 1-5.

[13] Huang, X., Qu, Y., Cid, C. A., Finke, C., Hoffmann, M. R., Lim, K., \& Jiang, S. C. (2016). Electrochemical disinfection of toilet wastewater using wastewater electrolysis cell. Water research, 92, 164-172.

[14] Md Yusof Hamid \& Suriani Ngah Abdul Wahab. (2012). Teori dan praktis pemeriksaan bangunan. Shah Alam, Selangor: Penerbit Universiti Teknologi Mara.

[15] Mohsin, M., Zargar, H. R., Bhat, T. A., Bhat, H. A., Mir, F. A., \& Wani, A. H. (2020). Open tendoachilles injuries due to squatting type of toilet seats: Five-year prospective observational study from a tertiary care center in India. Injury, 51(10), 2316-2321.

[16] Mydin, M. O., Salim, N. A., Tan, S. W., Tawil, N. M., \& Ulang, N. M. (2014). Assessment of significant causes to school building defects. In E3S Web of Conferences (Vol. 3, p. 01002). EDP Sciences.

[17] Okuntade, T. F. (2014). Effects of faulty design and construction on building maintenance. International Journal of Technology Enhancements and Emerging Research, 59-64. 
Qualitative Survey for Lavatory Spaces; Case Study on Toilet at Canselor Tuanku Muhriz's Hospital, The National University of Malaysia (UKM)

[18] Rathore, P., Sarmah, S. P., \& Singh, A. (2020). Location-allocation of bins in urban solid waste management: a case study of Bilaspur city, India. Environment, Development and Sustainability, 22(4), 3309-3331.

[19] Shittu, A. A., Adamu, A. D., Mohammed, A., Suleiman, B., Isa, R. B., Ibrahim, K., \& Shehu, M. A. (2013). Appraisal of building defects due to poor workmanship in public building projects in Minna, Nigeria. IOSR Journal of Engineering, 3(9), 30-38.

[20] Talib, R. (2014). Assessment of factors affecting building maintenance and defects of public buildings in Penang, Malaysia. Journal Scientific Academic Publishing, 48-53.

[21] Tan, S. W., Mydin, M. O., Sani, N. M., \& Sulieman, M. Z. (2014). Investigation into common decay of educational buildings in malaysia. In MATEC Web Of Conferences (Vol. 10, p. 05001). EDP Sciences. -

[22] Waziri, B.S. (2016), "Design and construction defects influencing residential building maintenance in Nigeria", Journal of Civil Engineering, Vol. 10 No. 3, pp. 313-323.

[23] Wei, P. and Thomas, R. (2015). Defects and their influencing factors of Posthandover NewBuild Homes. J. Perform. Constr. Facil. 29: 1-11. Doi: .1061/(ASCE)CF.19435509.0000618.

[24] World Toilet Organization. (2011). World Toilet Organization won gates foundation's support of USD270,000. Press release, 2011. http://worldtoilet.org/wpcontent/uploads/2014/02/gates foundation2.pdf. [Accessed: 17-May-2015].

[25] Yacob, S., Ali, A. S., \& Au-Yong, C. P. (2019). Establishing relationship between factors affecting building defects and building condition. Journal of Surveying, Construction and Property, 10(1), 31-41. 